Journal of Energy and
Environmental Sustainability
Journal homepage : www.jees.in

\title{
Evaluation of Biological Oxygen Demand (BOD) and Chemical Oxygen Demand (COD) Removal from Tannery Wastewater using Activated Carbon from Terminalia catappa Nutshells
}

\author{
L.G. Hassan ${ }^{1}$, A. Uba ${ }^{1}$, S. W. Hassan ${ }^{2}$ S. Yusuf ${ }^{1}$, M.A.Sokoto ${ }^{1 *}$ and A. N. Itodo ${ }^{3}$ \\ ${ }^{1}$ Department of Pure and Applied Chemistry, ${ }^{2}$ Department of Biochemistry, UsmanuDanfodiyo University, Sokoto; ${ }^{3}$ Department of Chemistry, \\ Federal University of Agriculture, Makurdi
}

\section{A R T I C L E I N F O}

Received : 01 August 2018

Revised : 01 October 2018

Accepted : 11 October 2018

Keywords:

Activated carbon, Adsorption, BOD, COD,

Tannery wastewater, Terminalia catappa.

\begin{abstract}
A B S T R A C T
In this present study, activated carbon was prepared from Terminalia catappa nutshell using two-step process with $\mathrm{H}_{3} \mathrm{PO}_{4}$ as activating agent. The derived adsorbent was investigated for $\%$ reduction of BOD and COD in tannery wastewater at different contact times. The results of characterization showed the ranges of \% yield, \% burn off, bulk density $\left(\mathrm{g} / \mathrm{cm}^{3}\right)$ and $\mathrm{pH}$ of activated carbons from nutshell to be $17.67 \pm 0.04$ to $28.94 \pm 0.07,71.06 \pm 0.02$ to $82.33 \pm 0.05,0.49 \pm 0.03$ to $0.57 \pm 0.01$ and $6.31 \pm 0.02$ to $6.64 \pm 0.01$ respectively, while ranges for conductivity $(\mathrm{iS} / \mathrm{cm}), \%$ moisture content and $\%$ ash content are $0.68 \pm 0.03$ to $1.51 \pm 0.01,4.20 \pm 0.03$ to $7.03 \pm 0.04$ and $6.50 \pm 0.03$ to $13.50 \pm 0.04$ respectively. The adsorbent was interacted with tannery wastewater using batch adsorption experiments and the percentage BOD and COD determined. The results of the reduction efficiency (\%) showed that $60.47 \%$ of BOD and $84.21 \%$ of COD reductions were attained at 120 minutes and 150 minutes of interaction times respectively. The adsorption kinetics followed pseudo second order kinetic. Hence, the activated carbons produced from Terminalia catappa nutshell can find application in various wastewater remediations.
\end{abstract}

(C) 2018 ISEES, All rights reserved

\section{Introduction}

Environmental pollution due to technological advancement and a structural shift toward increased industrialization is one of the major problems of this century. Leather processing is an important economic activity in many developing and developed countries. It has been estimated that the annual production of leather in the entire world is approximately 1.67 billion $\mathrm{m}^{2}$, with an estimated trade value of US $\$ 70$ billion (Sabumon, 2016). Since most of the developing countries are using the traditional leather processing, the characteristics of the effluents are similar (Sabumon, 2016). In 1980s, Nigeria was the African hub of tannery processes and leather works with over 40 functional tanneries. The tanneries in Nigeria are over-concentrated in Northern Nigeria, especially in the city of Kano, the commercial capital of the North. However, a few tanneries can be found in other northern cities such as Zaria, Sokoto, Maiduguri, and Potiskum. Commercial centres of the south have significant leather processing industries especially in places such as Aba, Onitsha, Lagos, Ibadan, and Port-Harcourt (Yusuf et al., 2012).

Leather tanneries waste can be categorized as wastewater, solid waste and air emissions. The characteristics of tannery wastewaters vary considerably from one tannery to other, depending on its size, chemicals used for a specific process, amount of water used and type of final products produced by a tannery. Tannery effluents are characterized by a high concentration of pollutants and a great variety of composition. There are considerable dissimilarities in the concentration range of pollutants in tannery wastewaters given by different authors (Ilou et al., 2012). Organic pollutants (proteic and lipidic components) are originated from skins (it is calculated that the raw skin has $30 \%$ loss of organic material during the working cycle) or they are introduced during processes (Islam et al., 2014). Tannery wastewater is highly polluted specifically in terms of chemical oxygen demand (COD) and biochemical oxygen demand (BOD). Their major pollutant is organic content, derived from hides and skins. Composite wastewater of tanneries carries COD values in a range of 3800-41300 mg/L (Awan, 2004). The presence of contaminated sites in populated areas is a major concern for urban development because the costs of soil remediation pose significant liabilities and financial burdens on landowners and other stakeholders (Karim et al., 2013). The various components present in the effluent also affects human beings, agriculture, and livestock besides causing severe ailments to the tannery workers such as eye diseases, skin irritations, kidney failure and gastrointestinal problems (Dargo and Ayalew, 2014). Sulphide, one of the major components of the tannery effluent causes irritation, rotten egg smell above $1 \mathrm{ppm}(1.4$ $\mathrm{mg} \mathrm{m}^{-3}$ ), and at concentrations above $10 \mathrm{ppm}$,it has toxicological effect on exposure limits are exceeded. Sulphide has high oxygen demand of 2 moles $\mathrm{O}_{2} / \mathrm{mol}$ sulphide and causes depletion of oxygen in water (Dargo and Ayalew, 2014). In Sokoto metropolis (the study area), the tanneries are mostly located in the midst of densely populated residential areas, thereby exposing the inhabitants of such areas to the obnoxious odour as well as many toxic chemicals and pathogenic microorganisms. The effluents may also get into underground water sources and this may pose

*Corresponding Author: abdullahimuhammadsokoto@gmail.com 
a possible health risk to the inhabitants of such areas (Rabah and Ibrahim, 2010). The present study was aimed at investigating the potential of Terminalia catappa shell as an adsorbent for organic pollutants in the tannery waste water.

\section{Materials and Methods}

\subsection{Sample Collection and Pre-Treatment}

The matured and sun-dried Terminalia catappa fruits (UDUH/ANS/ 0148) were collected by hand picking from the trees at Usmanu Danfodiyo University Sokoto, Nigeria. The fruits obtained were washed, dried and crushed to remove the nuts. The deseeded fruits were washed thoroughly with distilled water and dried in an oven at $105^{\circ} \mathrm{C}$ for 2 hours and further crushed to separate the pericarp from the shells. The shells were then pulverized into powder using mortar and pestle and sieved through a 2.0 $\mathrm{mm}$ mesh size. The sample with less than $2.0 \mathrm{~mm}$ was kept in an airtight container (Idris et al., 2013). Tannery wastewater sample was collected in a clean sample bottle $(2.5$ Litres) from local tannery at Unguwar Rogoarea in Sokoto metropolis. The collected sample was transported to the laboratory for further analyses.

\subsection{Production of Activated Carbon}

A known quantity of Terminalia catappa nutshell was placed into cleaned and pre-weighed crucibles. The crucibles were placed into a muffle furnace at $600{ }^{\circ} \mathrm{C}$ and allowed to stand for 5 minutes after which the crucibles were placed into an ice bath. The excess water was drained off. The carbonized sample was washed with $0.1 \mathrm{M} \mathrm{HCl}$ to remove the surface ash. It was further washed with hot distilled water for removal of the residual acid then dried in an oven at $100^{\circ} \mathrm{C}$ for 1 hour. These processes were repeated until a substantial amount of carbonized sample was obtained (Gimba et al., 2004 and Turoti et al., 2007).

\subsubsection{Activation of the Carbonized Sample}

The activation was achieved by mixing $5 \mathrm{~g}$ of the carbonized sample with $5 \mathrm{~cm}^{3}$ of the activation agent $\left(1 \mathrm{M} \mathrm{H}_{3} \mathrm{PO}_{4}\right)$. The mixture was allowed to stand for 2 hours, after which it was heated at $800{ }^{\circ} \mathrm{C}$ for 5 minutes in a furnace. The activated sample was cooled in an ice-cold bath, the excess water was drained off and the sample dried in an oven at $110^{\circ} \mathrm{C}$ overnight. The above procedure was repeated for different dwelling time (10 and 15 minutes) until substantial amount of each of the activated carbons was obtained. The activated samples were then washed with $0.1 \mathrm{M} \mathrm{HCl}$ to remove surface ash, followed by hot water wash and rising with distilled water to remove residual acid. Washing was completed when the $\mathrm{pH}$ of the supernatant fall within the range of 6-7, then the sample was dried in an oven at $110{ }^{\circ} \mathrm{C}$ overnight and stored in airtight container (Rahman et al., 2005),. The carbonization and activation processes are illustrated by equations 1 and 2 .

\section{Raw biomass $600{ }^{\circ} \mathrm{C} / 5 \mathrm{~min} . \longrightarrow \mathrm{C}+\mathrm{CO}_{2}$ (Carbonization)}

\section{$\mathrm{C}+\mathrm{AA} \quad \underline{800^{\circ} \mathrm{C} / 5,10 \text { and } 15 \text { mins. }} \mathrm{AC}+\mathrm{CO}_{2}$ (Activation)}

Where $\mathrm{AA}$ and $\mathrm{AC}$ are an activating agent and activated carbon respectively (Itodo, 2008)

\subsection{Determination of Physicochemical Parameters of the Activated Carbon}

The moisture and ash contents of the activated carbon were determined according to the method reported by Itodo (2008). A known gram of the activated carbon was weighed into a petri dish. The dish was placed in an oven at $105 \pm 5{ }^{\circ} \mathrm{C}$ for 4 hours. The dish was covered, cooled in a desiccator and weighed. The heating, cooling, and weighing were repeated at $30 \mathrm{~min}$. intervals until a constant weight was obtained. The percentage moisture content was calculated using equation 3.

$$
\text { Moisture content }(\% \text { by mass })=\frac{(\mathrm{W}-\mathrm{X})}{\mathrm{M}} \times 100
$$

Where $\mathrm{M}$ and $\mathrm{X}$ are the masses in grams of the materials taken for test and after drying respectively.

Ash content was determined by taking a known amount of the dried sample into a cleaned and dried crucible. The crucible was heated in a muffle furnace at $500{ }^{\circ} \mathrm{C}$ for 3 hours until grayish white ash was obtained. The content was then removed and cooled in a desiccator before weighing. The weight of the residue left after ashing was taken as the sample ash content. The percentage ash was calculated using equation 4 .

$$
\text { Ash }(\%)=\frac{\text { Weight of the ash }(\mathrm{g})}{\text { Weight of dry sample }(\mathrm{g})} \times 100
$$

\subsection{3 $\mathrm{pH}$ and Conductivity Measurement}

The $\mathrm{pH}$ was determined by pouring $20 \mathrm{~cm}^{3}$ of distilled water into each of three beakers containing $1 \mathrm{~g}$ of the activated carbon. These were then stirred thoroughly with a glass rod to uniformly wet the samples. The quantity of the water in each beaker was then increased to $100 \mathrm{~cm}^{3}$. The samples were stirred for 30 minutes and allowed to stand for an hour. The beakers were covered with clean watch glasses during the period. Ten (10) $\mathrm{cm}^{3}$ of the extract was decanted into a clean dried beaker. The $\mathrm{pH}$ was determined using $\mathrm{pH}$ meter, while the conductivities were taken using a conductivity meter at room temperature (Itodo, 2008).

\subsubsection{Bulk Density}

The bulk density of the activated carbon was estimated by placing the product into a graduated cylinder and compacted by tapping on the bench top until a constant volume was obtained (Aziza et al., 2008). The mass and the volume were recorded and the density was calculated using the equation 6 .

$$
\text { Density }=\frac{\text { Mass }(\mathrm{g})}{\text { Volume occupied }(\mathrm{cm} 3)}
$$

\subsubsection{Activation Burn Off}

This refers to the weight difference between the original raw sample and activated carbon divided by the weight of the original raw sample both on a dry basis (Ioannidou and Zabaniotou, 2006). The percentage burn off was calculated using equation 7 .

Percentage burn off $=\frac{\text { Mass of the raw material }- \text { Mass of activated carbon ) }}{\text { Mass of the raw material }} \times 100$

\subsubsection{Yield of Activated Carbon}

The yield of activated carbon was determined according to the method reported by Yulu et al., (2001) and calculated using equation 8 .

$$
\text { Percentage yield }(\%)=\frac{w}{w o} \times 100 \%
$$

Where $\mathrm{W}_{\mathrm{o}}$ and $\mathrm{W}_{\mathrm{i}}$ are Original mass of precursor and weight of activated carbon respectively.

\subsection{Batch Adsorption Studies}

In the adsorption studies, $2 \mathrm{~g}$ each of the activated carbons was mixed with $40 \mathrm{~cm}^{3}$ of each of the wastewater samples in a beaker and covered. These were allowed to stand for 30 minutes and then filtered using Whatman filter paper (No. 42). The process was repeated at pre-set times (60, 90,120 and 150 minutes). Each mixture was separately filtered and the filtrates collected. This was continued until $500 \mathrm{~cm}^{3}$ of each of the filtrates was obtained. The filtrates were used for the determination of BOD and COD (Hameed et al., 2006). The BOD and COD of the wastewater samples were also determined before interaction with the activated carbon. The BOD and COD experiments were conducted on the sampling dates (Hur et al., 2010).

\subsection{Determination of BOD of Wastewater Samples.}

To determine the BOD of the wastewater samples, $200 \mathrm{~cm}^{3}$ of each of the filtrates obtained from the interaction of activated carbon with each of the wastewaters were measured into a conical flask. One (1) $\mathrm{cm}^{3}$ of each of $\mathrm{MnSO}_{4}(\mathrm{aq})$ and alkali-iodide-azide solutions were added, shaken and allowed to settle. The clear liquid above the precipitates was decanted. Two (2) $\mathrm{cm}^{3}$ of conc. $\mathrm{H}_{3} \mathrm{PO}_{4}$ and water $\left(1.0 \mathrm{~cm}^{3}\right)$ were added to dissolve the precipitates. These were then titrated against $0.025 \mathrm{M}$ sodium thiosulphate. The titre values were recorded as the initial dissolve oxygen (initial DO). From the remaining filterates, $200 \mathrm{~cm}^{3}$ were measured into a darkened bottle and $1 \mathrm{~cm}^{3}$ of each of $\mathrm{MnSO}_{4}$ (aq) and alkali-iodideazide solution were also added. The content was kept for 5 -days at $20^{\circ} \mathrm{C}$. The clear liquids above each of the precipitates were decanted and $2 \mathrm{~cm}^{3}$ of conc. $\mathrm{H}_{3} \mathrm{PO}_{4}$ and water $\left(2.0 \mathrm{~cm}^{3}\right)$ were added to dissolve the precipitates. The sample was then titrated against $0.025 \mathrm{M}$ sodium thiosulphate. The titre values were then recorded as the final dissolve oxygen (Final DO). Equation 9 and 10 were used to calculte BOD and percentage BOD removal respectively.

$$
\begin{aligned}
& \mathrm{BOD}(\mathrm{mg} / \mathrm{l})=\text { Final DO- Initial DO } \\
& \% \mathrm{BOD} \text { removed }=\frac{\mathrm{BODi}-\mathrm{BODf}}{\mathrm{BODi}} \times 100
\end{aligned}
$$


Where, $\mathrm{BOD}_{\mathrm{i}}$ and $\mathrm{BOD}_{\mathrm{f}}(\mathrm{mg} / \mathrm{L})$ are $\mathrm{BOD}$ concentrations of tannery effluents before and after interaction with the adsorbent (Idris et al., 2013).

\subsection{Determination of COD of Wastewater Samples.}

The COD of the tannery wastewaters weredetermined by measuring $50 \mathrm{~cm}^{3}$ of each of the samples and placed into a $500 \mathrm{~cm}^{3}$ refluxing flask and glass boiling beads ( 5 pieces) were added which served as antibumping followed by the addition of $\mathrm{HgSO}_{4}$ crystals (1g). Into this solution, $5 \mathrm{~cm}^{3}$ of $\mathrm{H}_{2} \mathrm{SO}_{4} / \mathrm{Ag}_{2} \mathrm{SO}_{4}$ was also added and mixed until the $\mathrm{HgSO}_{4}$ dissolved.

A portion potassium heptaoxodichromate (VI) solution $(0.25 \mathrm{M})$ was added and the content was mixed thoroughly; while mixing, $70 \mathrm{~cm}^{3}$ of concentrated $\mathrm{H}_{2} \mathrm{SO}_{4}-\mathrm{Ag}_{2} \mathrm{SO}_{4}$ solution was also added.After thorough mixing, the flask was refluxed for 2 hours. The interior of the condenser and flask were washed with distilled water and the final volume was titrated against iron (II) ammonium tetraoxosulphate (VI) hexahydrate with ferroin indicator. The same procedure was repeated for the other samples. A blank sample determination was also carried out (Idris et al., 2012).

The COD of the respective samples were calculated using equation 11

$$
\operatorname{COD}\left(\frac{\mathrm{mg}}{\mathrm{L}}\right)=\frac{(\mathrm{A}-\mathrm{B}) \mathrm{M} \times 8000 \times \mathrm{F}}{\mathrm{V}}
$$

Where, $\mathrm{A}$ and $\mathrm{B}=$ volumes of $\mathrm{FeSO}_{4}\left(\mathrm{NH}_{4}\right)_{2} \mathrm{SO}_{4} \cdot 6 \mathrm{H}_{2} \mathrm{O}$ used for blank and sample determinations, volume of sample used $\left(\mathrm{cm}^{3}\right) ; \mathrm{F}=$ dilution factor of the sample. The COD was calculated using equation 12 .

$$
\text { COD removal }(\%)=\frac{\text { CODi }- \text { CODf }}{\text { CODi }} \times 100
$$

Where: $\mathrm{COD}_{\mathrm{i}}$ and $\mathrm{COD}_{\mathrm{f}}$ are $\mathrm{COD}$ concentrations of tannery wastewaters before and after interaction with the AC (mg/L) (Olafadehan et al., 2012).

\subsection{Determination of Adsorption Capacity}

The adsorption capacity at time $(\mathrm{t})$ was calculated using equation 13

$$
q_{t}=\frac{\left(C_{i}-C_{f}\right) V}{W}
$$

Where $C_{i}$ and $C_{f}$ are BOD/COD concentrations of the wastewater before and after interaction with the adsorbent $(\mathrm{mg} / \mathrm{L})$.

\subsubsection{Adsorption Kinetic Studies}

In order to evaluate the kinetic parameters, pseudo-first order and pseudo-second-order models were used to analyze the adsorption kinetics (Demirbas et al., 2004). Adsorption kinetics governs the solute uptake rate, measure the adsorption efficiency of the adsorbent, and determine its applicability for explaining the experimental data (Ghasemian andPalizban, 2016). Kinetic modeling not only allows estimation of sorption rates but also leads to suitable rate expressions characteristic of possible reaction mechanisms (Robati, 2013).

\subsubsection{Pseudo First Order Equation}

The pseudo first order equation in equation 14 .

$$
\frac{d q t}{u \iota}=k_{t}\left(q_{s}-q_{t}\right)
$$

Where: $q_{e}$ and $q_{t}$ are adsorption capacities at equilibrium and at time $t$, respectively $\left(\mathrm{mg} \cdot \mathrm{g}^{-1}\right) . K_{1}$ is the rate constant of pseudo first order adsorption $\left(\mathrm{min}^{-1}\right)$.

After integration and applying boundary conditions $\mathrm{t}=0$ to $\mathrm{t}=\mathrm{t}$ and qt $=0$ to $q_{t}=q_{e}$, the integrated form is expressed in equation 15

$$
\log \left(\mathrm{q}_{\mathrm{e}}-\mathrm{q}_{\mathrm{t}}\right)=\log (q e)-\frac{k_{1}}{2.303} t
$$

The values of $\log \left(q_{e} q_{t}\right)$ were linearly correlated with $t$. The plot of $\log \left(q_{q} q_{\text {. }}\right)$ versus $\mathrm{t}$ should give a linear relationship from which $k_{1}$ and $q_{t}$ can be determined from the slope and intercept of the plot, respectively (Demirbaset al., 2004). The slope $\left(-\mathrm{k}_{1} / 2.303\right)$ and intercept $\left(\log \left(\mathrm{q}_{\mathrm{e}}\right)\right)$ of plot $\log \left(\mathrm{q}_{\mathrm{e}}-\mathrm{q}_{\mathrm{t}}\right)$ versus $t$ was used to determine the pseudo first order constant $\mathrm{k}_{1}$ and the equilibrium adsorption capacity $\left(\mathrm{q}_{\mathrm{e}(\mathrm{cal})}\right)$. The slope $\left(1 / \mathrm{q}_{\mathrm{e}}\right)$ and intercept $\left(\left(1 / \mathrm{K}_{2} \mathrm{q}_{\mathrm{e}}{ }^{2}\right)\right.$ or $\left(\right.$ slope $\left.\left.^{2} / \mathrm{K}_{2}\right)\right)$ of the plot of $t / \mathrm{qt}$ versus $\mathrm{t}$ were used to calculate the parameters $\mathrm{K}_{2}$ and $\mathrm{q}_{\mathrm{e}(\mathrm{cal})}$ for the pseudo second order adsorption (Kumar, 2006 and Kyzas et al., 2014).

\subsubsection{The Pseudo Second-Order Equation}

The pseudo second- order adsorption kinetic rate equation (equation $1)$ is expressed as equation 16.

$$
\frac{d q_{t}}{d t}=k_{2}\left(q e-q_{t}\right)^{2}
$$

Where: $K_{2}$ is the rate constant of the pseudo second order adsorption $\left(\mathrm{g} \cdot \mathrm{mg}^{-1} \cdot \mathrm{min}^{-1}\right)$. For the boundary conditions $\mathrm{t}=0$ to $\mathrm{t}=\mathrm{t}$ and $\mathrm{q}_{\mathrm{t}}=0$ to $\mathrm{q}_{\mathrm{t}}$ $=\mathrm{q}_{\mathrm{e}}$, the integrated form of the equation becomes:

$$
\frac{1}{q \theta-q t}=\frac{1}{q \theta}+\mathrm{k}_{2} \mathrm{t}
$$

This is the integrated rate law for the pseudo second-order reaction. Equation 18 can be rearranged to the linear form as expressed in equation 18 :

$$
\left[\frac{t}{q_{t}}\right]=\frac{1}{k_{2 q_{\varepsilon}^{2}}}+\frac{1}{q_{\theta}}(t)
$$

If the initial adsorption rate, $\mathrm{h}\left(\mathrm{mg} \cdot \mathrm{g}^{-1} \cdot \mathrm{min}^{-1}\right)$ is:

$$
\mathrm{h}=\mathrm{k}_{2}(\mathrm{qe})
$$

then equation 18 become:

$$
\left[\frac{t}{q_{t}}\right]=\frac{1}{h}+\frac{1}{q_{\varepsilon}}(t)
$$

The plot of ( $t / q t)$ and $t$ of equation 20 should give a linear relationship from which qe and $\mathrm{k}_{2}$ can be determined from the slope and intercept of the plot, respectively (Demirbaset al., 2004). The slope $\left(-\mathrm{k}_{1} / 2.303\right)$ and intercept $\left(\log \left(q_{e}\right)\right)$ of plot $\log \left(q_{e}-q_{t}\right)$ versus $t$ was used to determined the pseudo first order constant $\mathrm{k}_{1}$ and the equilibrium adsorption capacity $\left(\mathrm{q}_{\mathrm{e}(\mathrm{cal})}\right)$. The slope $\left(1 / \mathrm{q}_{\mathrm{e}}\right)$ and intercept $\left(\left(1 / \mathrm{K}_{2} \mathrm{q}_{\mathrm{e}}{ }^{2}\right)\right.$ or $\left(\right.$ slope $\left.\left.^{2} / \mathrm{K}_{2}\right)\right)$ of the plot of $t / q_{t}$ versus $t$ were used to calculate the parameters $K_{2}$ and $q_{e}$ for the pseudo second order adsorption (Kumar, 2006 and Kyzas et al., 2014).

\subsubsection{Test of kinetic Model}

The applicability of pseudo first- order and pseudo second-order kinetic models were verified through the sum of error squares (SSE, \%) given by equation 21:

$$
\% \mathrm{SSE}=\sqrt{ } \sum\left(\mathrm{qe}_{(\text {exp })}-\mathrm{qe}_{(\text {cal })}\right)^{2} / \mathrm{N}
$$

Where $\mathrm{qe}_{\text {(exp) }}, \mathrm{q}_{\mathrm{e}(\text { cal) }}$ and $\mathrm{N}$ are adsorption capacities at equilibrium, experimental and calculated $(\mathrm{mg} / \mathrm{g})$ and number of data points respectively (Abechiet al., 2011).

\section{Results and Discussion}

\subsection{Physicochemical Parameters of the Derived Adsorbent}

Table 1 showed the percentage yields, percentage burn offs, bulk densities, conductivities, percentage moisture and ash contents of the activated carbons generated from nutshells of the Terminalia cappa fruits. The percentage yields of the activated carbons produced from nutshell at 5,10 and 15 minutes activation times, are $28.94 \pm 0.07 \%, 22.41 \pm 0.03$ and $17.67 \pm 0.04 \%$ respectively while the corresponding percentage burn offs are $71.06 \pm 0.02$, $77.59 \pm 0.03$ and $82.33 \pm 0.05$ respectively. The percentage burn offs increase with increase in activation time while the percentage yield decrease with increase in percentage burn offs. At longer activation time, more volatile substances are released which lead to increase in percentage burn offs with corresponding decrease in percentage yield.

From the results (Table 1), the percentage yield is low as a result of double thermal decomposition resulting from initial pyrolysis followed by activation (Itodo, 2008). The bulk densities of the carbons activated for 5,10 and 15 minutes are $0.56 \pm 0.02,0.49 \pm 0.03$ and $0.57 \pm 0.01$ (g/ $\mathrm{cm}^{3}$ ) respectively. These values are higher than the bulk density of 0.42 $\left(\mathrm{g} / \mathrm{cm}^{3}\right)$ of the activated carbon prepared from Thevetiaperuviana wood activated with phosphoric acid (Raffiea et al.,2012) and are lower than the bulk density of $0.62 \mathrm{~g} / \mathrm{cm}^{3}$ for the activated carbon prepared from palm kernel (Abechi et al., 2013). The bulk density is an important characteristic of the carbon and is invariably related to the starting material. It is an important parameter of powdered solids. The American Water Work Association has set a lower limit on bulk density at $0.25 \mathrm{~g} / \mathrm{ml}$ for activated carbon to be of practical use (Veena et al., 2012). The bulk density value of these activated carbons satisfies this condition. The percentage ash content of the carbons activated for 5,10 and 15 minutes are $6.5 \pm 0.03,13.00 \pm 0.06$ and $13.50 \pm 0.04$ respectively (Table 1 ). These 
Table 1: Physicochemical Parameters of AC produced from Terminalia Catappanutshells

\begin{tabular}{l|l|l|l}
\hline Parameter & $\mathrm{AC}_{1}$ & $\mathrm{AC}_{2}$ & $\mathrm{AC}_{3}$ \\
\hline Yield (\%) & $28.94 \pm 0.07$ & $22.41 \pm 0.03$ & $17.67 \pm 0.04$ \\
Burn off (\%) & $71.06 \pm 0.02$ & $77.59 \pm 0.03$ & $82.33 \pm 0.05$ \\
Bulk density $\left(\mathrm{g} / \mathrm{cm}^{3}\right)$ & $0.56 \pm 0.02$ & $0.49 \pm 0.03$ & $0.57 \pm 0.01$ \\
$\mathrm{pH}$ & $6.53 \pm 0.01$ & $6.31 \pm 0.02$ & $6.64 \pm 0.01$ \\
Conductivity (iS/cm) & $0.68 \pm 0.01$ & $1.51 \pm 0.01$ & $0.68 \pm 0.04$ \\
$\%$ Moist. Cont. & $5.50 \pm 0.06$ & $7.03 \pm 0.04$ & $4.20 \pm 0.03$ \\
$\%$ Ash content & $6.50 \pm 0.03$ & $13.00 \pm 0.06$ & $13.50 \pm 0.04$ \\
\hline
\end{tabular}

$\mathrm{AC}_{1}, \mathrm{AC}_{2}$, and $\mathrm{AC}_{3}$ are activated carbons prepared from nutshells activated for 5,10 and 15

are in agreement with the percentage ash contents of $15.73 \pm 1.66$ for banana empty fruits bunch (Sugumaran et al., 2012) and $15.12 \%$ for maize stem impregnated with phosphoric acid (Dada et al., 2012). The percentage ash contents of $2.94 \%$ for Lapsi seed stone activated carbon and $34.80 \%$ for Jatropha pericarp activated carbon activated with sodium chloride were both outside the range reported by Shrestha et al. (2012) and Okeola et al. (2012) respectively. The percentage moisture contents of the carbons activated for 5,10 and 15 minutes are $5.50 \pm 0.06,7.03 \pm 0.04$ and $4.50 \pm 0.03$ respectively. The moisture contents of $1.90 \%$ for used tea dust activated with phosphoric acid (Shalna and Yogamoorthi, 2015) and $0.27 \%$ for phosphoric acid activated Lapsi seed stone carbon (Shrestha et al., 2012) are lower than the observed values. The percentage moisture contents of $5.21 \%$ for banana empty fruits bunch activated carbon (Sugumaran et al., 2012) and $5.60 \%$ for kenaf core fiber activated with phosphoric acid (Shamsuddin et al., 2015) were within the range of the produced activated carbons while the moisture contents of $13.20 \%$ for Thevetia peruvianacarbon activated with phosphoric acid (Raffiea et al., 2012) is higher than the observed values for the produced activated carbons. Even though moisture content of the carbon has no effect on its adsorptive power, it dilutes the carbon and necessitates the use of additional weight carbon during treatment process (Raffiea et al., 2012). The conductivity test reveals the presence of impurities (ions) on the activated carbon. The conductivity values of the carbons activated for 5,10 and 15 minutes are $0.68 \pm 0.03,1.51 \pm 0.01$ and $0.68 \pm 0.04$ respectively. The conductivity value of $51.00 \pm 0.6(\mathrm{iS} / \mathrm{cm})$ for coconut shell activated carbon (Amuda and Ibrahim, 2006) and that of Delonixregia fruit pod which was $353.66 \pm 3.51$ (iS/cm) Sugumaran et al. (2012) are higher than the conductivity values of the produced activated carbons. The conductivity of $1.5 \pm 0.11 \mathrm{mS}$ for poultry droppings carbons activated with phosphoric acid for 10 minutes, Idris et al. (2013) is similar to that of the activated carbon produced from nutshell of Terminalia Catappa activated for 10 minutes. The low conductivity value of the produced adsorbents shows that they contain low leachable wastes which are undesirable.

\subsection{Effects of Contact Time on Percentage BOD and COD Reduction}

The maximum percentage of tannery waste water BOD reductions by carbons prepared from nut shell and activated for 5, 10 and 15 minutes are $59.29 \%, 53.49 \%$ and $60.47 \%$ at 150,150 and 120 minutes interaction times respectively (Fig. 1).

The activated carbon from nut shells of Terminalia catappa seem to be less efficient compared to carbon produced from rice husk with percentage BOD removal of $73.00 \%$ from tannery waste water (Swathi et al., 2014). The maximum percentage of tannery waste water COD reduced by carbons prepared from nut shell and activated for 5 minutes is $52.63 \%$ at 150 minutes interaction time as it was revealed in Figure 2. This figure further indicates optimal percentages of the COD reduction by carbons activated for 10 minutes to be $78.95 \%$ at the longest interaction time of 150 minutes. The highest COD reduction was shown by the carbon activated for 15 minutes $(84.21 \%$ ) which was found to be at the longest interaction time of 150 minutes. The percentage COD reductions in tannery wastewater by using activated carbons from rice husk were $68.00 \%$ and $81.50 \%$ which were reported by Swathi et al. (2014) and Sivakumar, (2015) respectively.

\subsection{Kinetic of Adsorption}

The pseudo first-order and pseudo second-order models (equations 15 and 20) were applied to the adsorption data. The results of kinetic parameters shown in Tables 2-5 indicate that there is conformity between experimental data and the model predicted.

The $\mathrm{R}^{2}$ value of pseudo second-order is higher compared to $\mathrm{R}^{2}$ values of the pseudo first-order kinetic model tested (Tables 6) according to the method adopted by (Rajappa et al., 2014).

The adsorption kinetic model of tannery wastewater followed pseudo second order with respect to BOD with correlation coefficient $\left(\mathrm{R}^{2}\right)$ value of 0.9139 and percentage sum of error squares (\% SSE) of 0.0308 (Table 2).

The kinetic model also followed second order with respect to COD with correlation coefficient $\left(\mathrm{R}^{2}\right)$ value of 0.9343 and first order with percentage sum of error squares (\% SSE) value of 0.1767 as shown in Table 6 . The close agreement of the qe(cal) and the qe(exp) values further favoured the second order adsorption kinetic model.

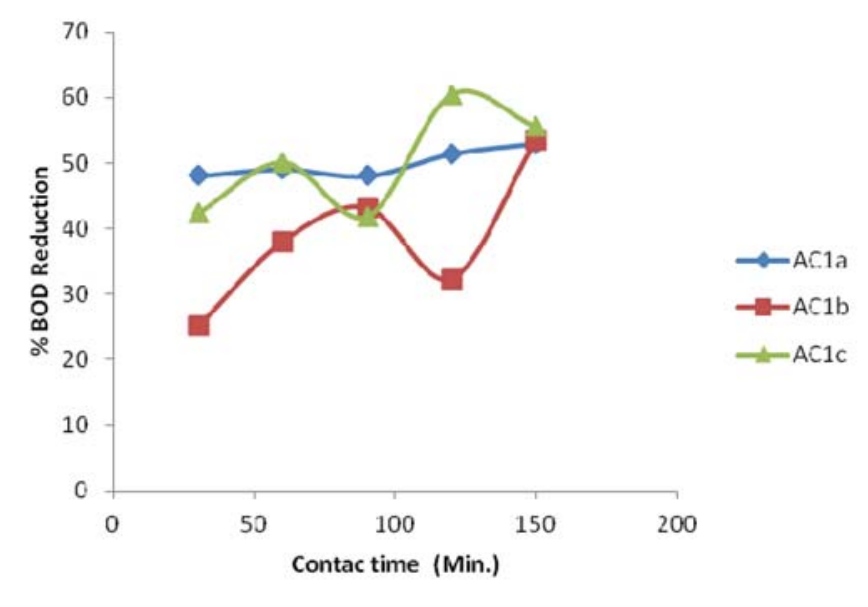

Figure 1: Effects of contact time on BOD removal by the ACs produced from the nutshells of Terminalia catappa.

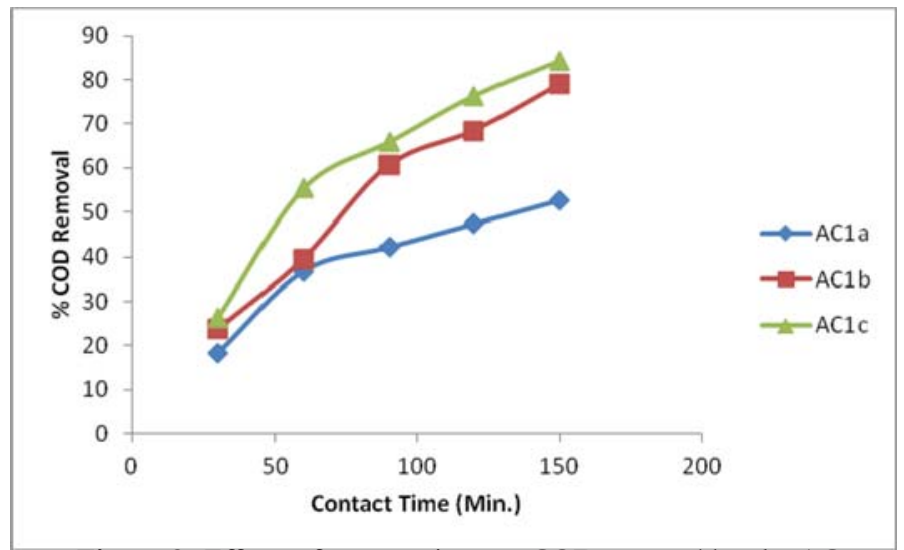

Figure 2: Effects of contact time on COD removal by the ACs produced from the nutshells of Terminalia Catappa

Table 2:Kinetic Studies experimental constants for the reduction of BOD from tannery wastewater using activated carbon (AC) produced from nutshell of Terminalia catappa

\begin{tabular}{l|l|l|l|l|l}
\hline Adsorbent & $\mathrm{R}^{2}$ & $\mathrm{~K}^{2}(\mathrm{~min}-1)$ & $\mathrm{qe}(\mathrm{cal}) \mathrm{mg} / \mathrm{g})$ & $\mathrm{qe}(\mathrm{exp}) \mathrm{mg} / \mathrm{g})$ & $\% \mathrm{SSE}$ \\
\hline $\mathrm{AC}_{1}$ & 0.14 & -0.0081 & 0.1 & 2.05 & 0.29 \\
$\mathrm{AC}_{2}$ & 0.002 & -0.0005 & 0.44 & 2.07 & 0.33 \\
$\mathrm{AC}_{3}$ & 0.514 & -0.0097 & 0.24 & 2.15 & 0.38 \\
\hline
\end{tabular}


Table 3: Kinetic Studies experimental constants for the reduction of COD from tannery wastewater using activated carbon (AC) produced from nutshell of Terminalia catappa

\begin{tabular}{l|l|l|l|l|l}
\hline \multirow{2}{*}{ Adsorbent } & \multicolumn{5}{|c}{ Experimental Constant } \\
\cline { 2 - 6 } & $\mathrm{R}^{2}$ & $\mathrm{~K}_{1}\left(\mathrm{~min}^{-1}\right)$ & $\mathrm{qe}(\mathrm{cal}).(\mathrm{mg} / \mathrm{g})$ & $\mathrm{qe}(\mathrm{exp}).(\mathrm{mg} / \mathrm{g}$ & $\% \mathrm{SSE}$ \\
\hline $\mathrm{AC}_{1}$ & 0.494 & 0.0101 & 2.47 & 4 & 0.31 \\
$\mathrm{AC}_{2}$ & 0.866 & 0.014 & 5.97 & 6 & 0.006 \\
$\mathrm{AC}_{3}$ & 0.786 & 0.0143 & 5.46 & 6.4 & 0.19 \\
\hline
\end{tabular}

Table 4: Kinetic Studies experimental constants for the reduction of TW BOD using AC produced from nutshell of Terminalia catappa

\begin{tabular}{l|l|l|l|l|l}
\hline Adsorbent & $\mathrm{R}^{2}$ & $\mathrm{~K}_{2}\left(\mathrm{~min}^{1}\right)$ & $\mathrm{qe}(\mathrm{cal}).(\mathrm{mg} / \mathrm{g})$ & $\mathrm{qe}(\mathrm{exp}).(\mathrm{mg} / \mathrm{g})$ & $\% \mathrm{SSE}$ \\
\hline $\mathrm{AC}_{1}$ & 0.995 & 0.0738 & 2.1 & 2.05 & 0.01 \\
$\mathrm{AC}_{2}$ & 0.709 & 0.0122 & 2.17 & 2.07 & 0.02 \\
$\mathrm{AC}_{3}$ & 0.907 & 0.0207 & 2.43 & 2.15 & 0.06 \\
\hline
\end{tabular}

Table 5: Kinetic Studies experimental constants for the reduction of TW COD using AC produced from nutshell of Terminalia catappa

\begin{tabular}{l|l|l|l|l|l}
\hline Adsorbent & $\mathrm{R}^{2}$ & $\mathrm{~K}_{2}\left(\mathrm{~min}^{1}\right)$ & $\mathrm{qe}(\mathrm{cal}).(\mathrm{mg} / \mathrm{g})$ & $\mathrm{qe}(\mathrm{exp}).(\mathrm{mg} / \mathrm{g})$ & $\% \mathrm{SSE}$ \\
\hline $\mathrm{AC}_{1}$ & 0.949 & 0.0014 & 6.81 & 4.00 & 0.56 \\
$\mathrm{AC}_{2}$ & 0.927 & 0.0003 & 15.20 & 6.00 & 1.84 \\
$\mathrm{AC}_{3}$ & 0.915 & 0.0005 & 12.80 & 6.40 & 1.30 \\
\hline
\end{tabular}

Table 6: Average Correlation Coefficients $\left(\mathrm{R}^{2}\right)$, Pseudo First and Second Order Statistical Sum of Errors (\%SSE)

\begin{tabular}{l|l|l|l|l}
\hline & $1^{\text {st }}$ order $\%$ SSE & $2^{\text {nd }}$ order $\%$ SSE & $1^{\text {st }}$ order $\mathrm{R}^{2}$ & $2^{\text {nd }}$ order $\mathrm{R}^{2}$ \\
\hline TW BOD & 0.3762 & 0.0308 & 0.2570 & 0.9139 \\
TW COD & 0.1767 & 1.1145 & 0.663 & 0.9343 \\
\hline
\end{tabular}

\section{Conclusions}

The results of the study revealed that the activated carbons produced from nutshells of Terminalia catappa activated with phosphoric acid are effective adsorbents for the adsorption of BOD and COD (organic pollutants) in tannery wastewater.The adsorption kinetic model of tannery wastewater followed pseudo second order with respect to BOD and second order with respect to COD These activated carbons produced can equally be used as alternatives to the commercial activated carbons in waste water treatment.

\section{References}

[1] Abechi, E.S, Gimba C.E, Uzairu A, Kagbu J.A. (2011). Kinetics of adsorption of methylene blue onto activated carbon prepared from palm kernel shell. Archives of Applied Science Research,3 (1):154-164

[2] Abechi, S.E., Gimba C.E, Uzairu A, Dallatu Y.A. (2013). Preparation and Characterization of Activated Carbon from Palm Kernel Shell by Chemical Activation.Research Journal of Chemical Sciences, 3(7), 54-61.

[3] Amuda, O. S. and Ibrahim A.O. (2006). Industrial wastewater treatment using natural material as an adsorbent. African Journal of Biotechnology. 5 (16), 1483-1487,

[4] Awan, A. M. (2004). Reduction of Chemical Oxygen Demand from Tannery wastewater by Oxidation. Electron Journal of Environmental, Agricultural and Food Chemistry. 3 (1), 625-628

[5] Aziza, A., Odiakosa, A., Nwajei, G. and Orodu, V. (2008). Modification and characterization of activated carbon derived from Bumper sawdust to remove lead (II) and Cadmium (II) effluents in water. CSN conference proceedings. Chemical Society of Nigeria. Deltachem 2008. pp235-243.

[6] Dada, A. O, Inyinbor, A. A, Oluyori, A. P. (2012). Comparative adsorption of dyes unto activated carbon prepared from maize stems and sugar cane stems. Journal of Applied Chemistry (IOSR-JAC)2(3), 38-43

[7] Dargo H. and Ayalew A. (2014). Tannery Waste Water Treatment: A Review. International Journal of Emerging Trends in Science and Technology. 01(09), 14881494

[8] Demirbas, E., Kobya, M., Senturk, E. and Ozkan, T. (2004). Adsorption Kinetics for the reduction of $\mathrm{Cr}$ (VI) from aqueous solutions on the activated carbons prepared from agricultural wastes. Water Resources. 30(4), 533-539
[9] Ghasemian, E., and Palizban, Z. (2016). Comparisons of azo dye adsorptions onto activated carbon and silicon carbide nanoparticles loaded on activated carbon. Int. J. Environ. Sci. Technol. 13, 501-512

[10] Gimba, C., Ocholi, O. Nok, A. (2004). Preparation of activated carbon from agricultural waste II: Cyanide binding with an activated carbon matrix from groundnut shell. Nigerian Journal of Scientific Research. 4(2),106-110

[11] Hameed, B. H., Din, A. T. M. and Ahmad, A. L. (2006). Adsorption of methylene blue onto bamboo-based activated carbon: kinetics and equilibrium studies. Journal of Hazardous Materials. 141,819-825

[12] Hur, J., Bo-Mi, L., Tae-Hwan, L., and Dae-Hee, P. (2010). Estimation of Biological Oxygen Demand and Chemical Oxygen Demand for combined Sewer systems using synchronous fluorescence spectra. Sensors. 10,2460-2471

[13] Idris, S., J. Yisa, A. U. Itodo, K. A. Popoola (2012). Application of carbonized poultry waste in the reduction of chemical oxygen demand (COD) from dye wastewater: kinetic study. Resources and Environment, 2(2), 51-55

[14] Idris, S., M. M. Ndamitso 1, E. B. Muhammad and T. O. Labade (2013). Adsorption Kinetic for the Reduction of Biochemical Oxygen Demand (BOD) From Dye Effluent onto Poultry Droppings Activated Carbon. British Journal of Applied Science \& Technology 3(3), 626-637, 2013

[15] Ilou, I., Suabi, S., and Digua, K. (2012). Quantification of pollution discharges from tannery wastewater and pollution reduction by Pre-treatment station. International Journal of Science and Research. 3(5),1706-1715

[16] Ioannidou, O. and Zabaniotou, A. (2006). Agricultural precursors for activated carbon production. Renewable and Sustainable Energy Review. 11(1):196-205.

[17] Itodo, A. U. (2008). Comparative Studies on the Preparation and Evaluation of Activated carbon from selected Animals and Agricultural Wastes (Unpublished Thesis),Usmanu Danfodiyo University, Sokoto.

[18] Islam, B. I., Musa, A. E., Ibrahim, E. H. Salma, A. A. Sharafa, and Babiker M. E. (2014) Evaluation and Characterization of Tannery Wastewater. Journal of forest products \& industries, 3(3), 141-150

[19] Karim R.,Manshoven S., Islam R., Gascon J. A., Ibarra M., DielsL., and Rahman M. (2013). Assessment of an Urban Contaminated Site from Tannery Industries in Dhaka City, Bangladesh. individual papers. Journal of Hazardous, Toxic, and Radioactive Waste, 17(1) 1-30.

[20] Kumar, K. V. (2006). Linear and non-linear regression analysis for the sorption Kinetic of methylene blue onto activated carbon. Journal of Hazardous Materials B 13:538-1544 
[21] Kyzas, G. Z., Nikolaos, K. L. and Margaritis, K. (2014). Adsorption/desorption of a dye by a chitosan derivative: Experiment and phenomenological modeling. ChemicalEngineering Journal. 248: 327-336

[22] Odebunmi. E. and Okeola, F. (2001). Preparation and Characterization of Activated Carbon from Waste Materials. Chemical Society of Nigeria.26(2):149-155.

[23] Oghenejoboh, K. M., Smith, O. O., and Evuensiri, O. O. (2016). Application of cassava peels activated carbon in the treatment of oil refinery wastewater- a comparative analysis. Journal of Ecological Engineering 17(2):52-58

[24] Okeola, O. F., Odebunmi, E.O. and Ameen, O. M. (2012). Comparison of Sorption Capacity and Surface area of Activated carbon Prepared from Jatropha curcas fruit pericarp and seed coat.Bull. Chem. Soc. Ethiop. 26(2), 171-180.

[25] Olafadehan, O. A., Jinadu, O.W., Salami, L. and Popoola O. T. (2012). Treatment of brewery wastewater effluent using activated carbon prepared from coconut shell. International Journal of Applied Science and Technology. 2(1):165-178.

[26] Rabah A. B. and Ibrahim M. L. (2010). Physicochemical and Microbiological Characterization of Soils Laden with Tannery Effluents in Sokoto, Nigeria. Nigerian Journal of Basic and Applied Science 18(1):65-71

[27] Raffiea, B. J., Palanisamy, P. N. and Sivakumar, P. (2012). Preparationand characterization of activated carbon from Thevetiaperuviana for the reduction of dyes from textile wastewater. Advances in Applied Science Research, 2012, 3 (1):377-383

[28] Rahman, A., Sa'ad, B., Shaidan, S. and Rizal, S. (2005). Adsorption characteristics of malachite green on activated carbon derived from rice husks produced by chemical and thermal processes. Bioresource Technology. 90(14): 1578-1583.

[29] Ram, S. L., Pravin, U. S., Deepali S. P. (2011). Study on physicochemical Parameters of Water effluents from Taloja industrial area of Mumbai, India. International Journal of Ecosystem. 1(1):1-9

[30] Rajappa, A., Ramesh, K., and Nandhakumar, V. (2014). Adsorption of Nickel (II) Ion From Aqueous Solution onto $\mathrm{ZnCl}_{2}$ Activated Carbon Prepared From DelonixRegia Pods (Flame Tree). International Journal of Chemical and Physical Sciences. 3( 6):42-52

[31] Robati, D. (2013). Pseudo-second-order kinetic equations for modeling adsorption systems for reduction of lead ions using multi-walled carbon nanotube. Journal of Nanostructure in Chemistry, 3:55

[32] Sabumon, P.C. (2016). Perspectives on Biological Treatment of Tannery Effluent.Advances in Recycling \& Waste Management: Open Access.2016 1(1).
[33] Shalna, T. and Yogamoorthi. A. (2015). Preparation and characterization of activated carbon from used tea dust in comparison with commercial activated carbon. International Journal of Recent Scientific Research. 6(2): 2750 - 2755

[34] Shamsuddin, M. S., Yusoff, N. R. N. and Sulaiman, M. A. (2015). Synthesis and characterization of activated carbon produced from kenaf core fiber using H3PO4 activation. 5th International Conference on Recent Advances in Materials, Minerals, and Environment (RAMM) \& 2nd International Postgraduate Conference on Materials, Mineral, and Polymer (MAMIP),4-6 August 2015.

[35] Shresta, R. M., Yandav, A. P., Pokharel B. P. and Pradhananga, R. R. (2012) Production and characterization of activated carbon from Lapsi (Choerospondiasaxillaris) seed stone by chemical activation with phosphoric acid. Research Journal of chemical sciences. 2(10) 80-86

Sivakumar, D. (2015). Hexavalent chromium reduction in a tannery industry wastewater using rice husk silica. Global J. Environ. Sci. Manage., 1 (1): 27-40,

[36] Sugumaran, P. V. Priya S., Ravichandran, P., and Seshadri, S. (2012). Production and Characterization of Activated Carbon from Banana Empty Fruit Bunch andDelonixregia. Fruit Pod. Journal of Sustainable Energy \& Environment 3:125132

[37] Swathi, M., Sathya, S. A., Aravind, S., Ashi, S. P.K, Gobinath, R. and Saranya, D. D. (2014). Adsorption studies on tannery wastewater using rice husk. Scholars Journal of Engineering and Technology (SJET). 2(2B):253-257

[38] Turoti, M., Gimba, C.E., Ocholi, O. and Nok, A. (2007). Effect of Different activation Methods on the Adsorption Characteristic of activated carbon from Khayasenegalensis fruits and DelonixRegia pod. Chemclass Journal. 1:107-112.

[39] Veena, D. B., Jahagirdar, A. A., Zulfiqar Ahmed M.N., (2012). Adsorption of Chromium on Activated Carbon Prepared from Coconut Shell. International Journal of Engineering Research and Applications (IJERA). 2 (5):364-370

[40] Yulu, D. Walawender, W., Fan, L. (2001). Activated carbon prepared from phosphoric acid activation of grain sorghum. Bioresource technology. 81(1): 45-52.

[41] Yusuf, A. R., Abdulkarim, B. I. and Sallau S. (2012). An inventory of hazardous materials in tannery and pulp industries in Nigeria. Africa Institute for the Environmentally Sound Management of Hazardous and other Waste. Federal ministry of environment. Retrieved from http://www.google.com.ng/search?q=an+ inventory+of+hazardous+materials+in+tannery+and+pulp+industries+in+ Nigeria+pdf\&client $=$ ms-opera-mini-android\&channel=new\&gws_rd= cr\&ei=wfUrWJD7D-rGgAaI3o6AAQ 